\title{
Direct Probing of Criegee Intermediates from Gas-Phase Ozonolysis Using Chemical Ionization Mass Spectrometry
}

\section{Berndt, Torsten}

2017-09-27

Berndt , T , Herrmann , H \& Kurten , T 2017 , ' Direct Probing of Criegee Intermediates from Gas-Phase Ozonolysis Using Chemical lonization Mass Spectrometry ' , Journal of the American Chemical Society, vol. 139 , no. 38 , pp. 13387-13392 . https://doi.org/10.1021/jacs.7b05849

http://hdl.handle.net/10138/307396

https://doi.org/10.1021/jacs.7b05849

acceptedVersion

Downloaded from Helda, University of Helsinki institutional repository.

This is an electronic reprint of the original article.

This reprint may differ from the original in pagination and typographic detail.

Please cite the original version. 


\title{
Direct probing of Criegee intermediates from gas-phase ozonolysis using chemical ionization mass spectrometry
}

\author{
Torsten Berndt* ${ }^{*}$, Hartmut Herrmann ${ }^{1}$ and Theo Kurtén ${ }^{2}$
}

Leibniz-Institute for Tropospheric Research, TROPOS, 04318 Leipzig, Germany.

${ }^{2}$ Department of Chemistry, University of Helsinki, 00014 Helsinki, Finland.

\begin{abstract}
Criegee intermediates (CIs), mainly formed from gas-phase ozonolysis of alkenes, are considered as atmospheric oxidants beside $\mathrm{OH}$ and $\mathrm{NO}_{3}$ radicals as well as ozone. Direct CI measurement techniques are inevitably needed for reliable assessment of CI's role in atmospheric processes. We found that CIs from ozonolysis reactions can be directly probed by means of chemical ionization mass spectrometry with a detection limit of about $10^{4}-10^{5}$ molecules $\mathrm{cm}^{-3}$. Results from quantum chemical calculations support the experimental findings. The simplest $\mathrm{CI}, \mathrm{CH}_{2} \mathrm{OO}$, is detectable as adduct with protonated ethers, preferably with protonated tetrahydrofuran. Kinetic measurements yielded k $\left(\mathrm{CH}_{2} \mathrm{OO}+\mathrm{SO}_{2}\right)=$ $(3.3 \pm 0.9) \times 10^{-11}$ and $\mathrm{k}\left(\mathrm{CH}_{2} \mathrm{OO}+\right.$ acetic acid $)=(125 \pm 0.30) \times 10^{-10} \mathrm{~cm}^{3}$ molecule ${ }^{-1} \mathrm{~s}^{-1}$ at $295 \pm 2 \mathrm{~K}$ in very good agreement with recent measurements using diiodomethane photolysis for $\mathrm{CH}_{2} \mathrm{OO}$ generation. Cls from the ozonolysis of cyclohexene, acting as surrogate for cyclic terpenes, are followed as protonated species (CI) $\mathrm{H}^{+}$using protonated amines as reagent ions. Kinetic investigations indicate a different reactivity of cyclohexene derived CIs compared with that of simple CIs, such as $\mathrm{CH}_{2} \mathrm{OO}$. It is supposed that the aldehyde group significantly influences the CI reactivity of the cyclohexene derived CIs. The direct CI detection method presented here should allow to study the formation and reactivity of a wide range of different CIs formed from atmospheric ozonolysis reactions.
\end{abstract}

\section{INTRODUCTION}

The gas-phase ozonolysis of alkenes in the atmosphere forms thermalized Criegee intermediates (CIs), which further react via unimolecular steps or bimolecular reactions with water vapor and trace gases. ${ }^{14}$ CIs are believed to play a significant role as atmospheric oxidants, especially for the oxidation of $\mathrm{SO}_{2}$ forming $\mathrm{H}_{2} \mathrm{SO}_{4}{ }^{2,5}$ Due to the complexity of the ozonolysis reaction, the determination of reaction parameters, such as CI formation yields and rate coefficients, is very challenging. ${ }^{2}$ Kinetic measurements based on indirect methods lead to rate coefficients of CI reactions, which are in most cases affected with high uncertainty. ${ }^{2,6}$

A breakthrough in the kinetic measurements has been achieved by using diiodomethane photolysis for $\mathrm{CH}_{2} \mathrm{OO}$ generation coupled with direct CI probing by means of synchrotron photoionization mass spectrometry. For $\mathrm{CH}_{2} \mathrm{OO}+\mathrm{SO}_{2}$, a rate coefficient of $(3.9 \pm 0.7) \times 10^{-11} \mathrm{~cm}^{3}$ molecule ${ }^{-1} \mathrm{~S}^{-1}$ at $293 \mathrm{~K}$ was obtained being orders of magnitude higher than reported before. ${ }^{7}$ A series of following kinetic studies, using the same approach for $\mathrm{CH}_{2} \mathrm{OO}$ generation but with different spectroscopic detection techniques, confirmed this large rate coefficient. ${ }^{8}$ The diio- doalkane photolysis technique has been successfully applied for $\mathrm{CH}_{3} \mathrm{CHOO}$ and $\left(\mathrm{CH}_{3}\right)_{2} \mathrm{COO}$ studies as well. ${ }^{9,10}$ However, it remains questionable whether this approach will be applicable for a wide range of CIs due to the limited availability of the corresponding diiodoalkanes.

While the direct observation of $\mathrm{CH}_{2} \mathrm{OO}$ from ethylene ozonolysis for high reactant concentrations was explained $^{11}$ and a few CI trapping methods are available, ${ }^{1}$ direct CI detection from ozonolysis reactions for close to atmospheric conditions has not been reported so far. The mass spectrometric and spectroscopic methods, as used for the CI measurements in the photolysis experiments, ${ }^{7,8}$ seem to be not sensitive enough for this task. For alkene ozonolysis, steady-state CI concentrations are expected on the order of $10^{8}$ molecules $\mathrm{cm}^{-3}$ or (clearly) smaller depending on the chosen reactant concentrations, see below.

Here we report on a direct and sensitive CI measurement technique based on atmospheric pressure - chemical ionization mass spectrometry that meets the requirements to probe CIs from atmospherically relevant ozonolysis reactions. Selected kinetic measurements were carried out to demonstrate the usability of this technique. 
Quantum-chemical calculations provided the needed proton affinities for a series of compounds as given in Table 1and information on cluster stabilities.

\section{EXPERIMENTAL}

2.1. Free-jet flow system. The experiments have been conducted in a free-jet flow system at a pressure of $1 \mathrm{bar}$ purified air and a temperature of $295 \pm 2 \mathrm{~K}^{13}$ The reaction time was $7.9 \mathrm{~s}$ in all experiments. This set-up allows the investigation of oxidation reaction for atmospheric conditions in absence of wall effects.

The free-jet flow system consists of an outer tube (length: $200 \mathrm{~cm}$, inner diameter: $15 \mathrm{~cm}$ ) and an inner tube (outer diameter: $9.5 \mathrm{~mm}$ ) equipped with a nozzle. Ozone premixed with the carrier gas ( $5 \mathrm{~L} \mathrm{~min}^{-1} \mathrm{STP}$ ) is injected through the inner tube into the main gas stream (95L $\mathrm{min}^{-1} \mathrm{STP}$ ), which contains the second reactant (ethylene or cyclohexene). Large differences of the gas velocities at the nozzle outflow (nozzle: $15.9 \mathrm{~m} \mathrm{~s}^{1}$; main flow: $0.13 \mathrm{~m} \mathrm{~s}$ $\left.{ }^{1}\right)$ and the nozzle geometry ensure rapid reactant mixing downstream the nozzle. Gas sample taking was carried out from the centre flow. The diffusion processes at $1 \mathrm{bar}$ air are too slow to transport a significant fraction of the reaction products out of the centre flow toward the walls within the reaction time of $7.9 \mathrm{~s}$.

Ozone was produced by passing $2 \mathrm{~L} \mathrm{~min}^{-1}$ (STP) air through an ozone generator (UVP OG-2) and blended with carrier gas to a total flow of $5 \mathrm{~L} \mathrm{~min}^{-1}$ (STP) taken as the feed for the inner tube. The ozone concentration after reactant mixing was followed at the tube outflow by means of a gas monitor (Thermo Environmental Instruments 49C). The concentration of cyclohexene was detected using a proton transfer reaction mass spectrometer (Ionicon, PTR-MS 500). ${ }^{1}$ Initial ozone concentrations were in the range $(7.1-67.4) \times 10^{10}$ molecules $\mathrm{cm}^{-3}$, ethylene: $(4.3-4660) \times 10^{11}$ molecules $\mathrm{cm}^{-3}$ and cyclohexene: (10 - 12.2) $\times 10^{12}$ molecules $\mathrm{cm}^{-3}$

2.2. Chemical ionization mass spectromentry. CI detection was carried out using a CI-APi-TOF mass spectrometer (chemical ionization - atmospheric pressure interface - time-of-flight; Airmodus, Tofwerk) sampling the centre flow from the flow system through a sampling inlet (length: $28 \mathrm{~cm}$, inner diameter: $16 \mathrm{~cm}$ ) with a rate of $10 \mathrm{~L} \mathrm{~min}^{-1}(\mathrm{STP}) .{ }^{13}$ Used reagent ions $\mathrm{XH}^{+}$were protonated ethers, i.e. $\mathrm{X} \equiv$ tetrahydrofuran or diethylether, or protonated amines, $\mathrm{X} \equiv \mathrm{n}$ - or tert.-butylamine or diethylamine. The reagent ions were produced in a $35 \mathrm{~L} \mathrm{~min}^{-1}$ (STP) flow of purified air containing $(8.4-30) \times 10^{11}$ molecules $\mathrm{cm}^{-3}$ of the corresponding reagent ion precursor $\mathrm{X}$. The relative humidity of the air was held at about $1 \%$. Ionization was carried out with the help of a ${ }^{241} \mathrm{Am}$ source. Formed reagent ions were guided into the sample flow, $10 \mathrm{~L} \mathrm{~min}^{-1}$ (STP), by an electric field. Reaction time for the ionmolecule reaction was 200 - $300 \mathrm{~ms}$.

Normalized signals were obtained by dividing the measured signals of the protonated $\mathrm{CI},(\mathrm{CI}) \mathrm{H}^{+}$, or the adduct with the reagent ion, $(\mathrm{CI}) \mathrm{XH}^{+}$, by the sum of the signals of the reagent ions $\mathrm{XH}^{+}$and $\mathrm{X}_{2} \mathrm{H}^{+}$.

The mass spectrometer voltage settings were optimized for low fragmentation in order to achieve maximum signal intensity of the desired cations. Mass to charge values are given using the Thomson unit (Th) where $1 \mathrm{Th}=1 \mathrm{u} / \mathrm{e}$.

2.3. Kinetic analysis. The measureable concentration of themalized Criegee intermediates (CI) under conditions in the absence of the CI self-reaction and bimolecular CI reactions with other reaction products is governed by its formation step and the unimolecular decomposition:

$$
\begin{array}{lll}
\mathrm{O}_{3}+\text { alkene } & \rightarrow & \mathrm{y}_{1} \mathrm{CI}+\ldots \\
\mathrm{CI} & \rightarrow & \text { products }
\end{array}
$$

The value $\mathrm{y}_{1}$ stands for the $\mathrm{CI}$ formation yield. In the presence of an additive $\mathrm{X}$, the $\mathrm{CI}$ is additionally consumed by the reaction with this species.

$$
\mathrm{CI}+\mathrm{X} \quad \rightarrow \quad \text { products }
$$

The solution of the resulting differential equations for pathways (1) - (3) leads to the expression:

$$
[\mathrm{C}]=\frac{1-\exp \left(-\left(\mathrm{k}_{2}+\mathrm{k}_{3}[\mathrm{X}]\right) \mathrm{t}\right)}{\mathrm{k}_{2}+\mathrm{k}_{3}[\mathrm{X}]} \mathrm{y}_{1} \mathrm{k}_{1}\left[\mathrm{O}_{3}\right] \text { [alkene] }
$$

The ratio of the CI concentration (or the CI signal) in presence and absence of the additive $\mathrm{X}$ for otherwise constant reaction conditions is given by equation (II):

$$
[\mathrm{C}]_{\mathrm{X}} /[\mathrm{Cl}]_{\mathrm{X}=0}=\frac{\mathrm{k}_{2}}{\mathrm{k}_{2}+\mathrm{k}_{3}[\mathrm{X}]} \frac{1-\exp \left(-\left(\mathrm{k}_{2}+\mathrm{k}_{3}[\mathrm{X}]\right) \mathrm{t}\right)}{1-\exp \left(-\mathrm{k}_{2} \mathrm{t}\right)}
$$

For $t>3 / k_{2}$ equation (II) becomes independent of $t$ for practical application and can be simplified in accordance with the steady-state approximation for CI:

$$
[\mathrm{C}]_{\mathrm{X}} /[\mathrm{CI}]_{\mathrm{X}=0}=\frac{1}{1+\frac{\mathrm{k}_{3}}{\mathrm{k}_{2}}[\mathrm{X}]}
$$

2.4. Determination of reacted ethylene and cyclohexene. The reaction conditions in the free-jet experiments (reactant conversion: $<1 \%$ ) did not allow to measure the amount of converted hydrocarbon. Concentrations of converted ethylene and cyclohexene from the ozonolysis reactions were calculated from the measured reactant concentrations and the reaction time $t$ according to:

$$
\begin{aligned}
& \Delta[\text { ethylene }]=\mathrm{k}_{1} \text { ethylene } \times\left[\mathrm{O}_{3}\right] \times\left[\mathrm{C}_{2} \mathrm{H}_{4}\right] \times \mathrm{t} \\
& \Delta[\text { cyclohexene }]=\mathrm{k}_{1, \text { cyclohexene }} \times\left[\mathrm{O}_{3}\right] \times\left[\mathrm{c}-\mathrm{C}_{6} \mathrm{H}_{10}\right] \times \mathrm{t}
\end{aligned}
$$


The rate coefficients at $295 \mathrm{~K}$ were taken from the literature ${ }^{15}$ : (unit: $\mathrm{cm}^{3}$ molecule ${ }^{-1} \mathrm{~s}^{-1}$ ) $\mathrm{k}_{1 \text { ethylene }}=1.58 \times 10^{-18}$, $\mathrm{k}_{1 \text {, cyclohexene }}=7.46 \times 10^{-17}$.

2.4. Quantum-chemical calculations. Proton affinities and selected ion-molecule binding enthalpies were computed using $\omega \mathrm{B} 97 \mathrm{X}-\mathrm{D} /$ aug-cc-pVTZ ${ }^{16}$ geometries and thermal enthalpy contributions together with $\operatorname{CCSD}(\mathrm{T})$ F12a/VTZ-F12 ${ }^{17}$ single-point energy corrections. $\omega$ B97X-D calculations were performed using Gaussian 09 Rev. D.018, while the coupled-cluster calculations were performed using Molpro 2012.119. See the SI for full computational details including the configurational sampling approach.

\section{RESULTS AND DISCUSSION}

3.1. $\mathbf{C H}_{2} \mathrm{OO}$. Beginning with $\mathrm{CH}_{2} \mathrm{OO}$, the primary idea was to detect the $\mathrm{CI}$ as protonated species $\left(\mathrm{CH}_{2} \mathrm{OO}\right) \mathrm{H}^{+}$ formed via $\mathrm{XH}^{+}+\mathrm{CH}_{2} \mathrm{OO} \rightarrow\left(\mathrm{CH}_{2} \mathrm{OO}\right) \mathrm{H}^{+}+\mathrm{X}$. Due to $\mathrm{CH}_{2} \mathrm{OO}$ 's relatively high proton affinity (PA) of 850 $855 \mathrm{~kJ} / \mathrm{mol}$ a reagent ion precursors $\mathrm{X}$ with an accordingly high PA can be applied to ensure a selective ionization process (Table 1). ${ }^{20,21}$ (Only substances with a PA higher than that of $\mathrm{X}$ can be protonated.)

Table 1. Calculated proton affinities $(298.15 \mathrm{~K})$ for the studied species and available literature data.

\begin{tabular}{|l|l|}
\hline Species & Proton affinity, kJ/mol \\
\hline \hline Tetrahydrofuran (THF) & $826.5 ; 822.2^{1}$ \\
\hline Diethylether & $824.8 ; 828.4^{21}$ \\
\hline $\mathrm{CH}_{2} \mathrm{OO}$ & $855.7 ; 850.6^{20}$ \\
\hline Formic acid & $742.3 ; 742.0^{21}$ \\
\hline Dioxirane & 657.3 \\
\hline \hline n-Butylamine & $9214 ; 9215^{21}$ \\
\hline tert.-Butylamine & $932.7 ; 934.1^{21}$ \\
\hline Diethylamine & $9518 ; 952.4^{21}$ \\
\hline syn-OHC($\left(\mathrm{CH}_{2}\right)_{4} \mathrm{CHOO}$ & 970.5 \\
\hline anti-OHC(CH$)_{4} \mathrm{CHOO}$ & 987.1 \\
\hline OHC $\left(\mathrm{CH}_{2}\right)_{4} \mathrm{COOH}$ & 884.7 \\
\hline $\mathrm{C}_{6}$-Dioxirane & 849.5 \\
\hline syn-/anti-SOZ & $774.7 /{ }^{*}$ \\
\hline cis-VHP & 850.1 or $867.2^{\S}$ \\
\hline trans-VHP & 833.2 or $882.3^{\S}$ \\
\hline
\end{tabular}

* anti form decomposes after protonation

$\S$ for explanations see the SI

Tetrahydrofuran, $\mathrm{PA}=822-826 \mathrm{~kJ} / \mathrm{mol}$, was found to form the reagent ion $\mathrm{XH}^{+} \equiv(\mathrm{THF}) \mathrm{H}^{+}$with good purity under our reaction conditions. The experiments revealed that the reaction (THF) $\mathrm{H}^{+}+\mathrm{CH}_{2} \mathrm{OO}$ predominantly yielded the adduct $\left(\mathrm{CH}_{2} \mathrm{OO}\right)(\mathrm{THF}) \mathrm{H}^{+}$. The formation of this adduct and of the protonation product $\left(\mathrm{CH}_{2} \mathrm{OO}\right) \mathrm{H}^{+}$with a ratio of $\sim 45$ strictly followed the expected $\mathrm{CH}_{2} \mathrm{OO}$ generation and was not influences by adding propane as $\mathrm{OH}$ radical scavenger (Figure D.

It is assumed that the signal at nominal 47 Th exclusively stands for $\left(\mathrm{CH}_{2} \mathrm{OO}\right) \mathrm{H}^{+}$since the isobaric reaction products formic acid and dioxirane cannot be protonated due to their distinctly lower PAs (Table 1). The binding enthalpies of formic acid and dioxirane to (THF) $\mathrm{H}^{+}$are also significantly weaker than that of $\mathrm{CH}_{2} \mathrm{OO}$ (see the $\mathrm{SI}$ ), implying that other adducts than $\left(\mathrm{CH}_{2} \mathrm{OO}\right)(\mathrm{THF}) \mathrm{H}^{+}$, if formed at all, are unlikely to be efficiently detected by the instrument.

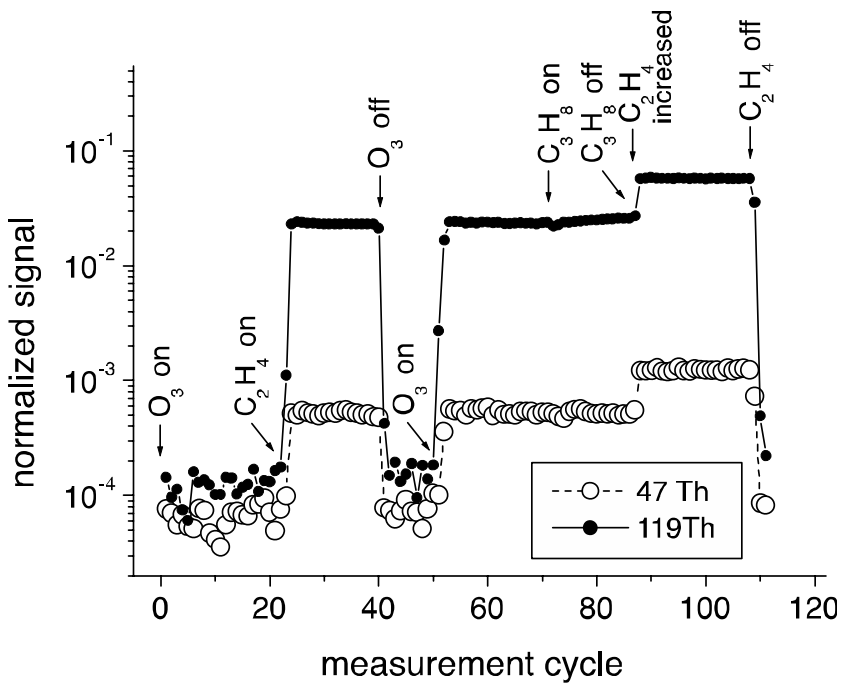

Figure 1. Measured ion traces at the nominal mass of 47 Th, $\left(\mathrm{CH}_{2} \mathrm{OO}\right) \mathrm{H}^{+}$, and at $119 \mathrm{Th},\left(\mathrm{CH}_{2} \mathrm{OO}\right)(\mathrm{THF}) \mathrm{H}^{+}$, as a function of different reactant conditions. A measurement cycle comprises $60 \mathrm{~s}$ signal accumulation. Reactant concentrations are: $\left[\mathrm{O}_{3}\right]=6.6 \times 10^{11} ;\left[\mathrm{C}_{2} \mathrm{H}_{4}\right]=10$ or $4.6 \times 10^{1 \text {; }}$, $\left[\mathrm{C}_{3} \mathrm{H}_{8}\right]=8.6 \times 10^{16}$ molecules $\mathrm{cm}^{-3}$.

We experimentally tested the possible detectability of formic acid by means of (THF) $\mathrm{H}^{+}$as the reagent ion. Neither a significant signal of the protonated formic acid nor a signal of the adduct with (THF) $\mathrm{H}^{+}$was observed for formic acid concentrations in the reaction gas of up to 19 $\times 10^{11}$ molecules $\mathrm{cm}^{-3}$ (SI Figure SD). This finding supports the chosen ionization scheme as a selective way for the detection of $\mathrm{CH}_{2} \mathrm{OO}$ in line with the theoretical calculations.

In a few experiments, diethylether with almost the same PA, was taken for the reagent ion production instead of THF. The non-cyclic ether was found to work in a similar way for $\mathrm{CH}_{2} \mathrm{OO}$ detection as shown for THF. No further reagent ions were tested.

3.11 Steady-state concentrations and detection limit. We measured the $\mathrm{CH}_{2} \mathrm{OO}$ adduct signal with (THF) $\mathrm{H}^{+}$, $\left(\mathrm{CH}_{2} \mathrm{OO}\right)(\mathrm{THF}) \mathrm{H}^{+}$, as a function of reacted ethylene by varying either ethylene for a constant ozone concentra- 
tion or vice versa. For an ethylene conversion $<10^{8}$ mole cules $\mathrm{cm}^{-3}$, both measurement series gave a joint straight line indicating the absence of significant bimolecular steps for $\mathrm{CH}_{2} \mathrm{OO}$ consumption (SI Figure $\mathrm{S} 2$ ). $\mathrm{CH}_{2} \mathrm{OO}$ concentrations for these measurements series were calculated according to equation (I) for $[\mathrm{X}]=0$ taking into account a CI formation yield of $0.40^{22}$, the reaction time of $7.9 \mathrm{~s}$ and $\mathrm{k}_{2, \mathrm{CH} 2 \mathrm{OO}}=0.19 \mathrm{~s}^{13 \mathrm{Ba}}$ (Figure 2).

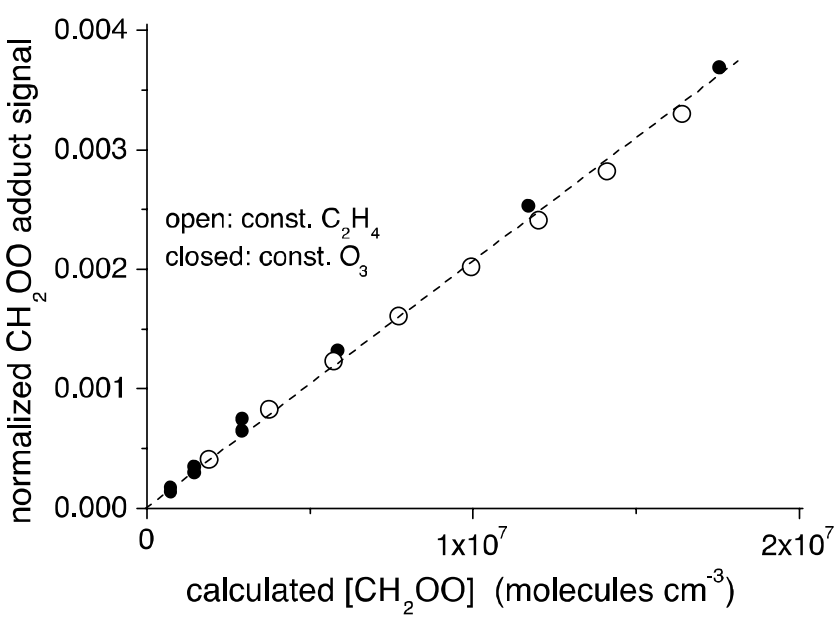

Figure 2. $\mathrm{CH}_{2} \mathrm{OO}$ adduct signal, $\left(\mathrm{CH}_{2} \mathrm{OO}\right)(\mathrm{THF}) \mathrm{H}^{+}$, as a function of calculated $\mathrm{CH}_{2} \mathrm{OO}$ steady-state concentration. Open symbols stand for a series using a constant ethylene concentration of $104 \times 10^{13}$ molecules $\mathrm{cm}^{-3}$ and variable ozone concentrations of up to $6.1 \times 10^{11}$ molecules $\mathrm{cm}^{-3}$. The closed symbols represent results for a constant ozone concentration of $6.55 \times 10^{11}$ molecules $\mathrm{cm}^{-3}$ and ethylene concentrations of up to $1.04 \times 10^{13}$ molecules $\mathrm{cm}^{-3}$.

A $\mathrm{CH}_{2} \mathrm{OO}$ detection limit of better than $10^{5}$ molecules $\mathrm{cm}^{-3}$ can be stated for a 10-minute integration time considering a measureable change of the normalized $\mathrm{CH}_{2} \mathrm{OO}$ adduct signal of about $10^{-5}$.

Furthermore, from the slope, normalized $\mathrm{CH}_{2} \mathrm{OO}$ adduct signal vs. $\left[\mathrm{CH}_{2} \mathrm{OO}\right]$ in Figure 2, a calibration factor $\mathrm{f}$ $=(4.8 \pm 0.2) \times 10^{9}$ molecules $\mathrm{cm}^{-3}$ can be obtained; $\left[\mathrm{CH}_{2} \mathrm{OO}\right]=\mathrm{f} \times$ normalized adduct signal. The calibration factor $\mathrm{f}$ is defined according to equation (VI), where $\mathrm{k}$ is the rate coefficient of the ion-molecule reaction (IMR), $t$ the IMR reaction time and the term $f_{\text {inlet }}$ considers the sample loss in the sampling tube.

$$
\mathrm{f}=1 /\left(\mathrm{k} \times \mathrm{t} \times \mathrm{f}_{\text {inlet }}\right)
$$

With $t=200-300 \mathrm{~ms}$ and $\mathrm{f}_{\text {inlet }}=0.88{ }^{13}$, the rate coefficient of the ion-molecule reaction, (THF) $\mathrm{H}^{+}+\mathrm{CH}_{2} \mathrm{OO}, \mathrm{k}$ $=(7.6-12.4) \times 10^{-10} \mathrm{~cm}^{3}$ molecule ${ }^{-1} \mathrm{~s}^{1}$ is calculated from the experimentally observed calibration factor $f$. This $k$-value is close to the collision limit of typical ion-molecule reactions. $^{23}$
On the other hand, further increase of the ethylene conversion up to $4 \times 10^{9}$ molecules $\mathrm{cm}^{-3}$ by increasing the ethylene addition leads to a distinct curvature of the $\mathrm{CH}_{2} \mathrm{OO}$ adduct signal due to the rising importance of the $\mathrm{CH}_{2} \mathrm{OO}$ self-reaction and other $\mathrm{CH}_{2} \mathrm{OO}$ consuming reactions with oxidation products or ethylene itself (SI Figure S3). ${ }^{13 a, 24}$ This experiment demonstrates the self-limiting, steady-state CI concentrations from ozonolysis reactions resulting in a maximum $\mathrm{CH}_{2} \mathrm{OO}$ concentration of about $3 \times 10^{8}$ molecules $\mathrm{cm}^{-3}$ in this case.

3.1.2. $\mathrm{CH}_{2} \mathrm{OO}$ kinetics. Kinetic measurements of the reactions of $\mathrm{CH}_{2} \mathrm{OO}$ with $\mathrm{SO}_{2}$ and acetic acid have been conducted under conditions of an ethylene conversion $<10^{8}$ molecules $\mathrm{cm}^{-3}$, i.e. in absence of unwanted bimolecular $\mathrm{CH}_{2} \mathrm{OO}$ steps (Figure 3). Hence, the $\mathrm{CH}_{2} \mathrm{OO}$ consumption was governed by the unimolecular decomposition and the reaction with the additive according to pathways (2) and (3). The reaction of $\mathrm{CH}_{2} \mathrm{OO}$ with the additives was followed by monitoring the $\mathrm{CH}_{2} \mathrm{OO}$ adduct signal, $\left(\mathrm{CH}_{2} \mathrm{OO}\right)(\mathrm{THF}) \mathrm{H}^{+}$, for rising concentrations of the additives.

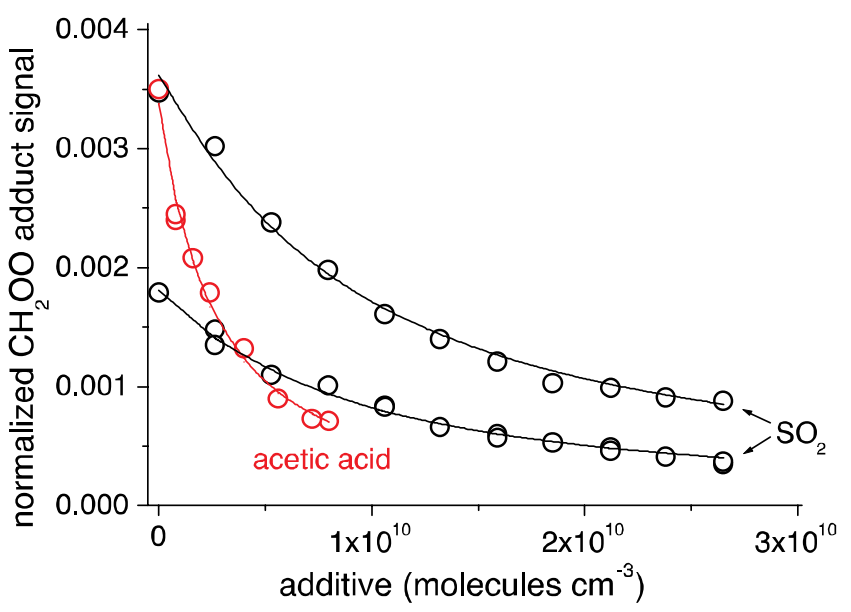

Figure 3. Kinetic measurements: $\left(\mathrm{CH}_{2} \mathrm{OO}\right)(\mathrm{THF}) \mathrm{H}^{+}$adduct signal as a functions of added $\mathrm{SO}_{2}$ or acetic acid. The lines represent the best-fit results of data analysis.

Applying $\mathrm{k}_{2, \mathrm{CH} 2 \mathrm{OO}}=(0.19 \pm 0.07) \mathrm{s}^{1 \mathrm{Ba}}$ and the reaction time $t=7.9 \mathrm{~s}$, the rate coefficient $\mathrm{k}_{3}$ was determined from the decreasing $\mathrm{CH}_{2} \mathrm{OO}$ signal for rising additions of the additive $\mathrm{X}$ according to equation (II). Nonlinear regression analysis for the determination of $\mathrm{k}_{3}$ was carried out with $\mathrm{k}_{2, \mathrm{CH} 2 \mathrm{OO}}=0.19,0.12$ and $0.26 \mathrm{~s}^{1}$ in order to take account the uncertainty of the input parameter $\mathrm{k}_{2, \mathrm{CH} 2 \mathrm{OO}}$ for the determination of $\mathrm{k}_{3}$. In the regression analysis the value $[\mathrm{CI}]_{\mathrm{X}=0}$ in equation (II) was set as free parameter. The results of the data analysis are summarized in Table 2. The stated final value of $\mathrm{k}\left(\mathrm{CH}_{2} \mathrm{OO}+\mathrm{SO}_{2}\right)$ represents a mean value and the given uncertainty comprises the whole range of uncertainties as obtained from the range of $\mathrm{k}_{2, \mathrm{CH} 20 \mathrm{OO}}$. The value $\mathrm{k}\left(\mathrm{CH}_{2} \mathrm{OO}+\mathrm{SO}_{2}\right)=(3.3 \pm 0.9) \times 10^{-11}$ $\mathrm{cm}^{3}$ molecule ${ }^{-1} \mathrm{~S}^{-1}$ is in good agreement with the results of direct $\mathrm{CH}_{2} \mathrm{OO}$ detection methods using diiodomethane 
photolysis for $\mathrm{CH}_{2} \mathrm{OO}$ generation, which span a range of (3.3 - 4.1) $\times 10^{-11} \mathrm{~cm}^{3}$ molecule ${ }^{-1} \mathrm{~s}^{1}$ at room temperature with individual uncertainties of up to $18 \%{ }^{7,8}$ For the reaction with acetic acid we measured $\mathrm{k}\left(\mathrm{CH}_{2} \mathrm{OO}\right.$ +acetic acid $)$ $=(1.25 \pm 0.30) \times 10^{-10} \mathrm{~cm}^{3}$ molecule ${ }^{-1} \mathrm{~s}^{-1}$ being in good agreement with the literature data of $(12 \pm 0.1) \times 10^{-10}$ or $(13 \pm 0.1) \times 10^{-10} \mathrm{~cm}^{3}$ molecule ${ }^{-1} \mathrm{~s}^{1.25}$

Table 2. Results of data analysis from the kinetic experiments of the reaction of $\mathrm{CH}_{2} \mathrm{OO}$ with $\mathrm{SO}_{2}$ or acetic acid

\begin{tabular}{|c|c|c|}
\hline & $\begin{array}{c}\mathrm{k}_{2, \mathrm{CH} 2 \mathrm{OO}} \\
\left(\mathrm{s}^{-1}\right)\end{array}$ & $\begin{array}{c}\mathrm{k}_{3} \equiv \mathrm{k}\left(\mathrm{CH}_{2} \mathrm{OO}+\mathrm{SO}_{2}\right) \\
\left(\mathrm{cm}^{3} \text { molecule }^{-1} \mathrm{~s}^{-1}\right)\end{array}$ \\
\hline \multirow{3}{*}{$\begin{array}{l}\text { higher initial } \\
\mathrm{CH}_{2} \mathrm{OO}\end{array}$} & 0.19 & $(3.16 \pm 0.16) \times 10^{-11}$ \\
\hline & 0.12 & $(2.71 \pm 0.12) \times 10^{-11}$ \\
\hline & 0.26 & $(3.69 \pm 0.21) \times 10^{-11}$ \\
\hline \multirow[t]{3}{*}{ lower initial $\mathrm{CH}_{2} \mathrm{OO}$} & 0.19 & $(3.43 \pm 0.15) \times 10^{-11}$ \\
\hline & 0.12 & $(2.91 \pm 0.11) \times 10^{-11}$ \\
\hline & 0.26 & $(4.02 \pm 0.19) \times 10^{-11}$ \\
\hline \multirow[t]{6}{*}{ average } & & $(3.3 \pm 0.9) \times 10^{-11}$ \\
\hline & & $\begin{array}{c}\mathrm{k}_{3} \equiv \mathrm{k}\left(\mathrm{CH}_{2} \mathrm{OO}+\text { acetic }\right. \\
\text { acid }) \\
\left(\mathrm{cm}^{3} \text { molecule }{ }^{-1} \mathrm{~s}^{-1}\right)\end{array}$ \\
\hline & 0.19 & $(1.23 \pm 0.10) \times 10^{-10}$ \\
\hline & 0.12 & $(104 \pm 0.09) \times 10^{-10}$ \\
\hline & 0.26 & $(144 \pm 0.11) \times 10^{-10}$ \\
\hline & & $(1.25 \pm 0.30) \times 10^{-10}$ \\
\hline
\end{tabular}

3.2. $\mathrm{C}_{2^{-}}$and $\mathrm{C}_{3}$-Criegee intermediates. The $\mathrm{CH}_{3} \mathrm{CHOO},\left(\mathrm{CH}_{3}\right)_{2} \mathrm{COO}$ and $\mathrm{CH}_{3} \mathrm{CH}_{2} \mathrm{CHOO}$ Criegee Intermediates were found to have proton affinities around 40-80 kJ/mol higher than $\mathrm{CH}_{2} \mathrm{OO}$. However, their clusters with (THF) $\mathrm{H}^{+}$were found to be significantly less stable than $\left(\mathrm{CH}_{2} \mathrm{OO}\right)(\mathrm{THF}) \mathrm{H}^{+}$(see the SI). No experimental effort was undertaken for a selective probing of the $\mathrm{C}_{2}$ and $\mathrm{C}_{3}$ CIs.

3.3. $\mathrm{C}_{6}$-Criegee intermediates from the ozonolysis of cyclohexene. Next, we turned to the detection of CIs arising from cyclic alkenes, such as from the terpenes $\alpha$ pinene and limonene, selecting cyclohexene as the simplest surrogate. Again, the idea was to probe the CIs as protonated species $(\mathrm{CI}) \mathrm{H}^{+}, \mathrm{XH}^{+}+\mathrm{CI} \rightarrow(\mathrm{CI}) \mathrm{H}^{+}+\mathrm{X}$. Expected CIs from cyclohexene ozonolysis are the syn- and anti-conformers $\mathrm{OHC}\left(\mathrm{CH}_{2}\right)_{4} \mathrm{CHOO}^{26}$ with a calculated PA of 970.5 and $987.1 \mathrm{~kJ} / \mathrm{mol}$, respectively. A series of amines, i.e. n- and tert.-butylamine and diethylamine with PAs in the range of 921 - $952 \mathrm{~kJ} / \mathrm{mol}$, appeared to be well-suited precursors for the reagent ions $\mathrm{XH}^{+}$(Table 1 ).

The exceptionally high proton affinity of $\mathrm{OHC}\left(\mathrm{CH}_{2}\right)_{4} \mathrm{CHOO}$ is related to strong electrostatic interactions between the aldehyde-group oxygen and the
Criegee-group carbon in the $\mathrm{OHC}\left(\mathrm{CH}_{2}\right)_{4} \mathrm{CHOOH}^{+}$cation, as illustrated in Chart 1 This 7-membered ring stabilizes the cationic form by several tens of $\mathrm{kJ} / \mathrm{mol}$.
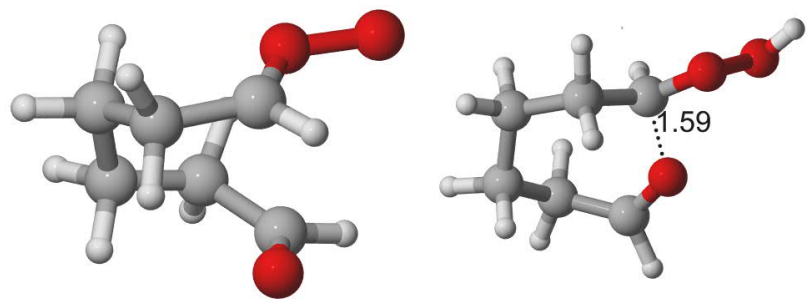

Chart 1. Lowest-energy structures of the neutral (left) and protonated (right) anti-OHC( $\left(\mathrm{CH}_{2}\right)_{4} \mathrm{CHOO}$ Criegee intermediate. The distance between the aldehyde-group oxygen and the Criegee-group carbon is given in Ångström.

A linearly rising signal with increasing cyclohexene conversion was observed at nominal 131 Th for protonated CIs, $(\mathrm{CI}) \mathrm{H}^{+}$, using the corresponding aminium cations $\mathrm{XH}^{+}$generated from of the chosen amines (Figure 4). Almost identical signal strengths emerged for $\mathrm{n}$ - and tert.butylammonium while for diethylammonium the signals were substantially weaker. It can be speculated that in the latter case merely a fraction of the CIs, maybe the anticonformer only, was efficiently protonated due to the relatively high PA of diethylamine. For n- and tert.butylammonium, however, the good agreement of the signal intensities points to an overall probing of both conformers by each amine. Isobaric $\mathrm{C}_{6} \mathrm{H}_{10} \mathrm{O}_{3}$ products like the aldehyde group containing acid $\left(\mathrm{OHC}\left(\mathrm{CH}_{2}\right)_{4} \mathrm{COOH}\right)$, the dioxirane, possible secondary ozonides (SOZ) or vinyl hydroperoxides (VHP) ${ }^{26}$ cannot influence the $(\mathrm{CI}) \mathrm{H}^{+}$signal due to their relatively low PAs, which do not enable protonation under the chosen conditions (Table 1 and explanation in SI).

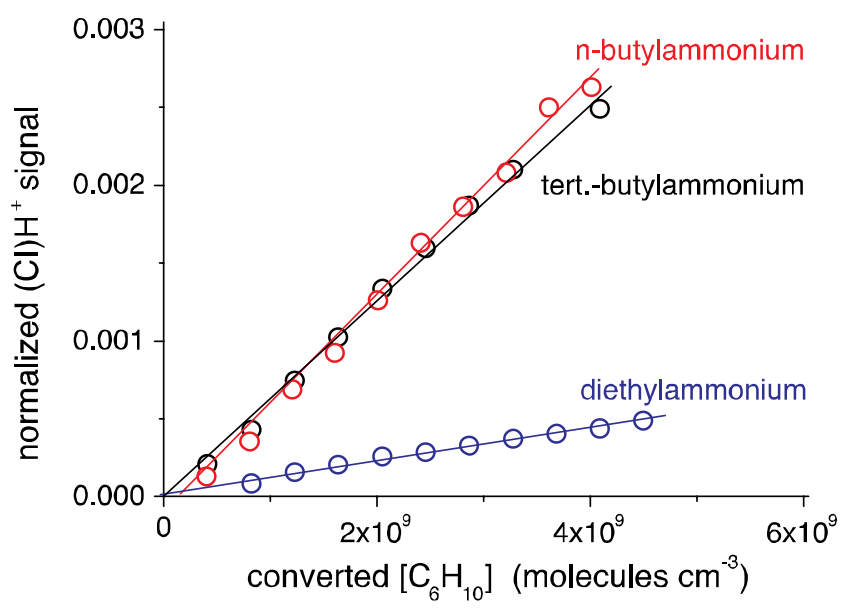

Figure 4. Normalized signal of protonated CIs, (CI) $\mathrm{H}^{+}$, at nominal 131 Th, syn- and anti-OHC( $\left.\mathrm{CH}_{2}\right)_{4} \mathrm{CHOO}$ in total, as a function of reacted cyclohexene. Reagent ions are different protonated amines. 
It should be noted that besides the protonated CIs a considerable signal at the adduct mass $\left(\mathrm{C}_{6} \mathrm{H}_{10} \mathrm{O}_{3}\right)(\mathrm{X}) \mathrm{H}^{+}$ emerged for all aminium ions $(\mathrm{X}) \mathrm{H}^{+}$as well. It was impossible to get a measureable signal reduction by addition of $\mathrm{SO}_{2}$ or other CI reactants. Thus, other products than the CIs must be responsible for these signals.

3.3.1. Kinetic experiments. The disappearance of the total syn- and anti-OHC( $\left(\mathrm{CH}_{2}\right)_{4} \mathrm{CHOO}$ signal, $(\mathrm{CI}) \mathrm{H}^{+}$, was measured for different additives using tert.butylammonium as the reagent ion (Figure 5).

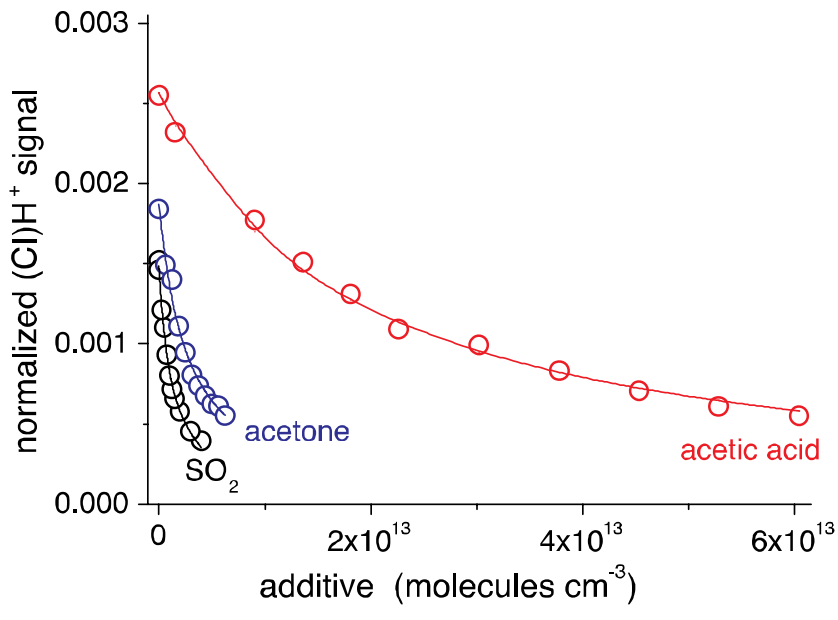

Figure 5. Kinetic measurements: Total signal of protonated syn- and anti-OHC( $\left(\mathrm{CH}_{2}\right)_{4} \mathrm{CHOO},(\mathrm{CI}) \mathrm{H}^{+}$, as a functions of added $\mathrm{SO}_{2}$, acetone or acetic acid. Tert.butylammonium served as the reagent ion. The lines represent the best-fit results of data analysis.

The data analysis has been perform using equation (III) and the value $[\mathrm{CI}]_{\mathrm{X}=0}$ was set again as free parameter in the regression analysis. The resulting rate coefficient ratios are $\mathrm{k}\left(\mathrm{C}_{6}-\mathrm{CI}+\right.$ add $) / \mathrm{k}_{3, \mathrm{C} 6-\mathrm{CI}}=(8.0 \pm 0.7) \times 10^{-13},(3.8 \pm$ $0.5) \times 10^{-13}$ and $(5.7 \pm 0.5) \times 10^{-4} \mathrm{~cm}^{3}$ molecule $^{-1}$ for the additives $\mathrm{SO}_{2}$, acetone and acetic acid, respectively. The best-fit curves are able to describe the experimental data very well in the whole measurement range. This fact indicates that either the rate coefficient ratios of the syn- and anti-conformer are similar or that one conformer dominates the total amount of the CIs. The observed CI reactivity order from these measurements is $\mathrm{k}\left(\mathrm{C}_{6}-\mathrm{CI}+\mathrm{SO}_{2}\right) /$ $\mathrm{k}\left(\mathrm{C}_{6}\right.$-CI + acetone $) / \mathrm{k}\left(\mathrm{C}_{6}\right.$-CI + acetic acid $)=1 / 0.48 /$ 0.07 being clearly different compared with that of $\mathrm{CH}_{2} \mathrm{OO}$, i.e. 1/ 0.01/ 3.7.7,13a,24 At the moment it is hard to give a justifiable explanation for this discrepancy. The calculations and measurements demonstrate that the aldehyde group in the cyclohexene derived CIs has a large effect on the proton affinity. It is thus not unreasonable to suppose that it could also significantly influences the CI reactivity toward various trace gases.

3.3.2. Detection limit. A rough estimate has been done concerning the steady-state $\mathrm{C}_{6}$-CI concentrations, syn- and anti-conformer in total, based on the measurements with tert.-butylammonium taking account of a CI yield of $0.03^{27,2 b}$. The needed rate coefficient $\mathrm{k}_{3, \mathrm{C} 6 \text {-CI }}$ was set at 125 $\mathrm{s}^{1}$ for both conformers based on available data for synand anti- $\mathrm{CH}_{3} \mathrm{CHOO}^{28}$ According to that, estimated $\mathrm{C}_{6}-\mathrm{CI}$ concentrations according to equation (I) for the measurements given in Figure 5 are in the range of $10^{5}-10^{6}$ molecules $\mathrm{cm}^{-3}$. Therefore, a detection limit of about $10^{4}$ molecules $\mathrm{cm}^{-3}$ or better can be assumed considering a measureable change of the normalized $(\mathrm{CI}) \mathrm{H}^{+}$signal of about $10^{-5}$ for a 10 -minute integration time. Such a detection limit is in line with the corresponding limits for other organic compounds using a similar mass spectrometric technique. ${ }^{13}$

\section{Conclusion}

In summary, we have experimentally demonstrated the direct probing of thermalized Criegee intermediates (CIs) formed from the gas-phase ozonolysis of alkenes for close to atmospheric reaction conditions. The analysis has been carried out by means of chemical ionization mass spectrometry using protonated ethers or amines as reagent ions. A CI detection limit of about $10^{4}-10^{5}$ molecules $\mathrm{cm}^{-3}$ was estimated for the chosen examples. Results of quantum-chemical calculations confirmed the experimental findings and discovered structural features of ionized CIs. While the calculations especially on CI species are most likely affected with larger uncertainties than experimentally obtained PAs, the huge PA differences between the considered CIs and their isobaric compounds of many tens or even hundreds of $\mathrm{kJ} / \mathrm{mol}$ strongly indicate that the species detected with the chosen reagent ions were indeed the CI. Similarly, the relatively weak binding of other isobaric $\mathrm{CH}_{2} \mathrm{O}_{2}$ species to (THF) $\mathrm{H}^{+}$, and the lack of a $(\mathrm{HCOOH})(\mathrm{THF}) \mathrm{H}^{+}$signal in experiments with formic acid, also indicate that the $\left(\mathrm{CH}_{2} \mathrm{O}_{2}\right)(\mathrm{THF}) \mathrm{H}^{+}$adduct signal detected at $119 \mathrm{Th}$ is solely due to $\left(\mathrm{CH}_{2} \mathrm{OO}\right)(\mathrm{THF}) \mathrm{H}^{+}$.

The direct $\mathrm{CI}$ detection method, as demonstrated here for the simplest $\mathrm{CI}, \mathrm{CH} 2 \mathrm{OO}$, and for the CIs arising from cyclohexene, allows to study the chemistry of Criegee intermediates for atmospheric conditions. This experimental approach coupled with the needed theoretical calculations should be applicable for a wide range of different CIs formed from atmosphenic ozonolysis reactions.

\section{ASSOCIATED CONTENT}

The Supporting Information is available free of charge on the ACS Publications website.

Experimental, Methods, Results of quantum-chemical calculations (log files), Kinetic analysis, Additional figures.

\section{AUTHOR INFORMATION}

Corresponding Author

*berndt@tropos.de 
Notes

The authors declare no competing financial interest.

\section{ACKNOWLEDGMENT}

The authors thank K. Pielok and A. Rohmer for technical assistance. TK thanks the Academy of Finland for funding and the CSC IT Center for Scienœe for computer resources.

\section{REFERENCES}

(1) Cox, R. A.; Penkett, S. A. Nature, 1971, 230, 321

(2) Calvert, J. G.; Atkinson, R.; Kerr, J. A.; Madronich, S.; Moortgat, G. K; Wallington, T. J.; Yarwood, G. The Mechanisms of Atmospheric Oxidation of the Alkenes, Oxford University Press, Oxford, 2000.

(3) Johnson, D.; Marston, G. Chem. Soc. Rev. 2008, 37, 699.

(4) Osborn, D. L; Taatjes, C. A. Int. Rev. Phys. Chem. 2015, 34, 309.

(5) Mauldin III, R. L.; Berndt, T.; Sipilä, M.; Paasonen, P.; Petäjä, T.; Kim, S.; Kurtén, T.; Stratmann, F.; Kerminen, V.-M.; Kulmala, M. Nature 2012, 488, 193.

(6) (a) Johnson, D.; Levin, A. G.; Marston, G. J. Phys. Chem. A 2001, 105, 2933. (b) Berndt, T.; Jokinen, T.; Mauldin III, R. L; Petäjä, T.; Herrmann, H.; Junninen, H.; Paasonen, P.; Worsnop, D. R.; Sipilä, M. J. Phys. Chem. Lett. 2012, 3, 2892.

(7) Welz, O.; Savee, J. D.; Osborn, D. L; Vasu, S. S.; Pencival, C. J.; Shallcross, D. E; Taatjes, C. A. Science 2012, 335, 204.

(8) (a) Sheps, L. J. Phys. Chem. Lett. 2013, 4, 4201 (b) Stone, D.; Blitz, M.; Daubney, L; Howes, N. U. M.; Seakins, P. Phys. Chem. Chem. Phys. 2014, 16, 1139. (c) Chhantyal-Pun, R; Davey, A.; Shallcross, D. E.; Percival, C. J.; Orr-Ewing, A. J. Phys. Chem. Chem. Phys. 2015, 17, 3617. (d) Huang, H.-L.; Chao, W.; Lin, J. J.M. Proc. Nat. Acad. Sci. U.S.A. 2015, 112, 10857.

(9) Taatjes, C. A.; Welz, O.; Eskola, A. J.; Savee, J. D.; Scheer, A. M.; Shallcross, D. E.; Rotavera, B.; Lee, E. P. F.; Dyke, J. M.; Mok, D. K. W.; Osborn, D. L.; Percival, C. J. Science 2013, 340, 177.

(10) Smith, M. C.; Chao, W.; Takahashi, K.; Boering, K. A.; Lin, J. J.-M. J. Phys. Chem. A 2016, 120, 4789.

(11) Womack, C. C.; Martin-Dumel, M.-A.; Brown, G. G.; Field, R. W.; McCarthy, M. C. Sci. Adv. 2015, doi: 10.1126/sciadv.1400105.

(12) (a) Horie, O.; Schäfer, C.; Moortgat, G. K. Int. J. Chem. Kinet. 1999, 31, 261 (b) Drozd, G. T.; Donahue, N. M. J. Phys. Chem. A 2011, 115, 4381 (c) Giorio, C.; Campbell, S. J.; Bruschi, M.; Tampieri, F.; Barbon, A.; Toffoletti, A.; Tapparo, A.; Paijens, C.; Wedlake, A. J.; Grice, P.; Howe, D. J.; Kalberer, M. J. Am. Chem. Soc. 2017, 139, 3999.

(13) (a) Berndt, T.; Kaethner, R.; Voigtländer, J.; Stratmann, F.; Pfeifle, M.; Reichle, P.; Sipilä, M.; Kulmala, M.; Olzmann, M. Phys. Chem. Chem. Phys. 2015, 17, 19862. (b) Berndt, T.; Richters, S.; Jokinen, T.; Hyttinen, N.; Kurtén, T.; Otkjær, R. V.; Kjaergaard, H. G.; Stratmann, F.; Herrmann, H.; Sipilä, M.; Kulmala, M.; Ehn, M. Nat. Commun. 2016, 7, 13677.

(1) Lindinger, W.; Hansel, A.; Jondan, A. Int. J. Mass Spectrometry Ion Processes 1998, 173, 191

(15) (a) Atkinson, R; Baulch, D. L; Cox, R. A.; Hampson, Jr., R. F.; Kerr, J. A.; Rossi, M. J.; Troe, J. J. Phys. Chem. Ref. Data 1997, 26, 521 (b) Greene, C. R.; Atkinson, R. Int. J. Chem. Kinet. 1992, 24, 803.

(16) (a) Chai, J. D.; Head-Gordon, M. Phys. Chem. Chem. Phys. 2008, 10, 6615. (b) Dunning, T. H. J. Chem. Phys. 1989, 90, 1007. (c) Kendall, R. A.; Dunning, T. H.; Harrison, R. J. J. Chem. Phys. 1992, 96, 6796.
(17) Adler, T. B.; Knizia, G.; Werner, H.-J. J. Chem. Phys. 2007, 127, 221106.

(18) Frisch, M. J.; Trucks, G. W.; Schlegel, H. B.; Scuseria, G. E.; Robb, M. A.; Cheeseman, J. R.; Scalmani, G.; Barone, V.; Mennucci, B.; Petersson, G. A.; Nakatsuji, H.; Caricato, M., Li, X.; Hratchian, H. P.; Izmaylov, A. F.; Bloino, J.; Zheng, G.; Sonnenberg, J. L.; Hada, M.; Ehara, M.; Toyota, K; Fukuda, R; Hasegawa, J.; Ishida, M.; Nakajima, T.; Honda, Y.; Kitao, O.; Nakai, H.; Vreven, T.; Montgomery, Jr., J. A.; Peralta, J. E.; Ogliaro, F.; Bearpark, M.; Heyd, J. J.; Brothers, E.; Kudin, K. N.; Staroverov, V. N.; Kobayashi, R.; Normand, J.; Raghavachari, K; Rendell, A.; Burant, J. C.; Iyengar, S. S.; Tomasi, J.; Cossi, M.; Rega, N.; Millam, J. M.; Klene, M.; Knox, J. E.; Cross, J. B.; Bakken, V.; Adamo, C.; Jaramillo, J.; Gomperts, R.; Stratmann, R. E.; Yazyev, O.; Austin, A. J.; Cammi, R.; Pomelli, C.; Ochterski, J. W.; Martin, R. L.; Morokuma, K.; Zakrzewski, V. G.; Voth, G. A.; Salvador, P.; Dannenberg, J. J.; Dapprich, S.; Daniels, A. D.; Farkas, Ö.; Foresman, J. B.; Ortiz, J. V.; Cioslowski, J.; Fox, D. J. Gaussian 09, Revision D.01; Gaussian, Inc.: Wallingford, CT, 2009.

(19) Werner, H.-J.; Knowles, P. J.; Knizia, G.; Manby, F. R; Schütz, M.; Celani, P.; Konona, T.; Lindt, R; Mitrushenkov, A.; Rauhut, G.; Shamasundar, K. R.; Adler, T. B.; Amos, R. D.; Bernhardsson, A.; Berning, A.; Cooper, D. L.; Deegan, M. J. O.; Dobbyn, A. J.; Eckert, F.; Goll, E.; Hampel, C.; Hesselmann, A.; Hetzer, G.; Hrenar, T.; Jansen, G.; Köppl, C.; Liu, Y.; Lloyd, A. W.; Mata, R. A.; May, A. J.; McNicholas, S. J.; Meyer, W.; Mura, M. E; Nicklass, A.; O'Neill, D. P.; Palmieri, P.; Peng, D.; Pflüger, K.; Pitzer, R.; Reiher, M.; Shiozaki, T. ; Stoll, H.; Stone, A. J.; Tarroni, R.; Thorsteinsson, T.; Wang, M. MOLPRO, version 2012.1, a package of ab initio programs; 2012; see http://www.molpro.net.

(20) Nguyen, M. T.; Nguyen, T. L; Ngan, V. T.; Nguyen, H. M. T. Chem. Phys. Lett. 2007, 448, 183.

(21) Hunter, E. P. L; Lias, S. G. J. Phys. Chem. Ref. Data 1998, 27,413 .

(22) (a) M. J. Newland, M. J.; Rickard, A. R.; Alam, M. S.; Vereecken, L.; Munoz, A.; Rodenas M.; Bloss, W. J. Phys. Chem. Chem. Phys. 2015, 17, 4076. (b) Berndt, T.; Voigtländer, J.; Stratmann, F.; Junninen, H.; Mauldin III, R. L.; Sipilä, M.; Kulmala, M.; Herrmann, H. Phys. Chem. Chem. Phys. 201, 16, 19130.

(23) (a) Mackay, G. I.; Bohme, D. K. Intern. J. Mass Spectrom. Ion Phys. 1978, 26, 327. (b) Tanner, S. D.; Mackay, G. I.; Bohme, D. K. Can. J. Chem. 1979, 57, 2350.

(24) (a) Taatjes, C. A.; Welz, O.; Eskola, A. J.; Savee, J. D.; Osborn, D. L.; Lee, E. P. F.; Dyke, J. M.; Mok, D. K. W.; Shallcross, D. E.; Percival, C. J. Phys. Chem. Chem. Phys. 2012, 14, 10391 (b) Buras, Z. J.; Elsamra, R. M. I.; Jalan, A.; Middaugh, J. E.; Green, W. H. J. Phys. Chem. A 201, 118, 1997.

(25) Welz, O.; Eskola, A. J.; Sheps, L.; Rotavera, B.; Savee, J. D.; Scheer, A. M.; Osborn, D. L; Lowe, D.; Booth, A. M.; Xiao, P.; Khan, M. A. H.; Percival, C. J.; Shallcross, D. E.; Taatjes, C. A. Angew. Chem. Int. Ed. 2014, 126, 4635.

(26) Donahue, N. M.; Drozd, G. T.; Epstein, S. A.; Presto, A. A.; Kroll, J. H. Phys. Chem. Chem. Phys. 2011, 13, 10848.

(27) Hatakeyama, S.; Kobayashi, H.; Akimoto, H. J. Phys. Chem. 1984, 88, 4736.

(28) (a) Fenske, J. D.; Hasson, A, S.; Ho, A. W.; Paulson, S. E. J. Phys. Chem. A 2000, 104, 9921 (b) Sheps, L; Scully, A. M.; Au, K. Phys. Chem. Chem. Phys. 2014, 16, 26701 
Authors are required to submit a graphic entry for the Table of Contents (TOC) that, in conjunction with the manuscript title, should give the reader a representative idea of one of the following: A key structure, reaction, equation, concept, or theorem, etc., that is discussed in the manuscript. Consult the journal's Instructions for Authors for TOC graphic specifications.

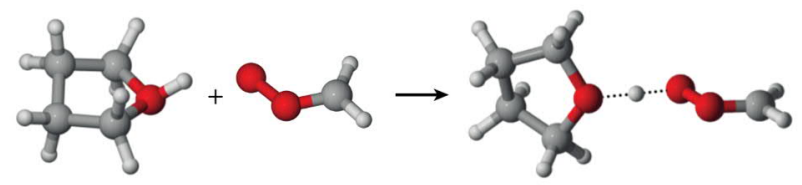

